\title{
The Unexplored Link between Communication and Trust in Aviation Maintenance Practice
}

\author{
Anna V. Chatzi *(D), Wayne Martin, Paul Bates ${ }^{(1)}$ and Patrick Murray \\ School of Commerce, University of Southern Queensland, Brisbane QLD4300, Australia; \\ waynem999@gmail.com (W.M.); paul.bates@usq.edu.au (P.B.); patrick.murray@usq.edu.au (P.M.) \\ * Correspondence: anna.chatzi@usq.edu.au; Tel.: +61-7-4631-2285
}

Received: 30 April 2019; Accepted: 30 May 2019; Published: 3 June 2019

\begin{abstract}
Communication and trust are fundamental factors in the operation of complex and highly regulated industries like aviation maintenance. This article reviews two preconditions of human error: communication and trust, as well as the way these are linked as aviation researchers have only recently started to study factors not individually, but rather by combining their effects. Communication is essential in the exchange of information and knowledge in aviation maintenance. The conditions that make communication effective and miscommunication avoidable are explored. Next, ways of communication, like aircraft maintenance documentation, are discussed along with appreciation of how communication is valued in aviation maintenance. Trust within different aspects of maintenance practice (interpersonal trust, trust towards technology, initial levels of trust) is presented and analysed, as well as examined as a prerequisite of effective communication. The characteristics of trust, its forms and results are identified in the literature with limited sources from the aviation bibliography, as it is a domain barely explored. Therefore, a gap has been identified in the study of trust and the exploration of the combined traits of communication and trust in aviation maintenance. Recommendations for additional research in this field are provided.
\end{abstract}

Keywords: human factors; communication; trust; safety; aviation maintenance; error

\section{Introduction}

To err is within human nature. However, it is primarily over the last 50 years that human error has become a field of scientific research, as errors started to have a great global impact in the economy, health, environment and communities. In the US alone, from over $\$ 300$ billion spent on maintenance and operations every year, $80 \%$ was spent repairing damage caused by human error in equipment, systems and dealing with harm caused to people [1,2]. In 2014 alone, there were 648 fatalities in 14 fatal accidents caused by human error. This number was $1.5 \%$ higher than the previous 10 years average. This increase was the result of larger airplanes, with larger passenger capacity which has led to an increase of fatalities in the occurrence of an accident [3], therefore, since human error led to higher numbers of human loss, there is a necessity within the aviation community to address this issue even more urgently.

A greater understanding of human factors became imperative within aviation, and a large number of models and systems have been introduced and implemented in the continuous attempt to predict and reduce human error. In aviation maintenance, there are twelve principal preconditions or conditions that contribute to human errors, widely known as the Dupont's Dirty Dozen [4-9]. These elements (shown in Figure 1) are dissimilar in nature and appear either on personal, group or organizational performance levels [10].

The Dirty Dozen is still used in training, accident, and human error analysis in aviation maintenance worldwide $[4,5,7,8,11]$. These 12 factors are of a different nature and quantifiability, nevertheless 
each one of them represents a precondition/condition to failure in the user's judgement and as such they are treated either individually or in groups of similar items [8]. As shown in Figure 1 lack of communication is among these 12 most frequent conditions/preconditions of human error.

Researchers still investigate elements similar to the ones of the Dirty Dozen, but also consider mutual interactions. As a most recent example, the Joint Research Program in the European Union (EU) 'Future Sky Safety', aims to study the concept of the Human Performance Envelope (HPE) in aviation. This research is investigating the interactions between nine human factors (stress, attention, situation awareness (SA), vigilance, teamwork, workload, communication, trust, fatigue) and the pilot's human performance, how they work individually or in combination, and how they affect or decline human performance [12].

Communication has been indicated by past research to have a strong association with trust [13]. Trust is an important element in human social life and therefore, has been researched extensively in the past by many different disciplines of science such as marketing, psychology, sociology, political science, economics, etc. [14]. Many researchers agree that trust is a very important element in employees' relations and it is associated with the quality of their communication [15-22]. Trust is under-investigated in aviation [19] and its association with communication is an unexplored area, especially in aviation maintenance.
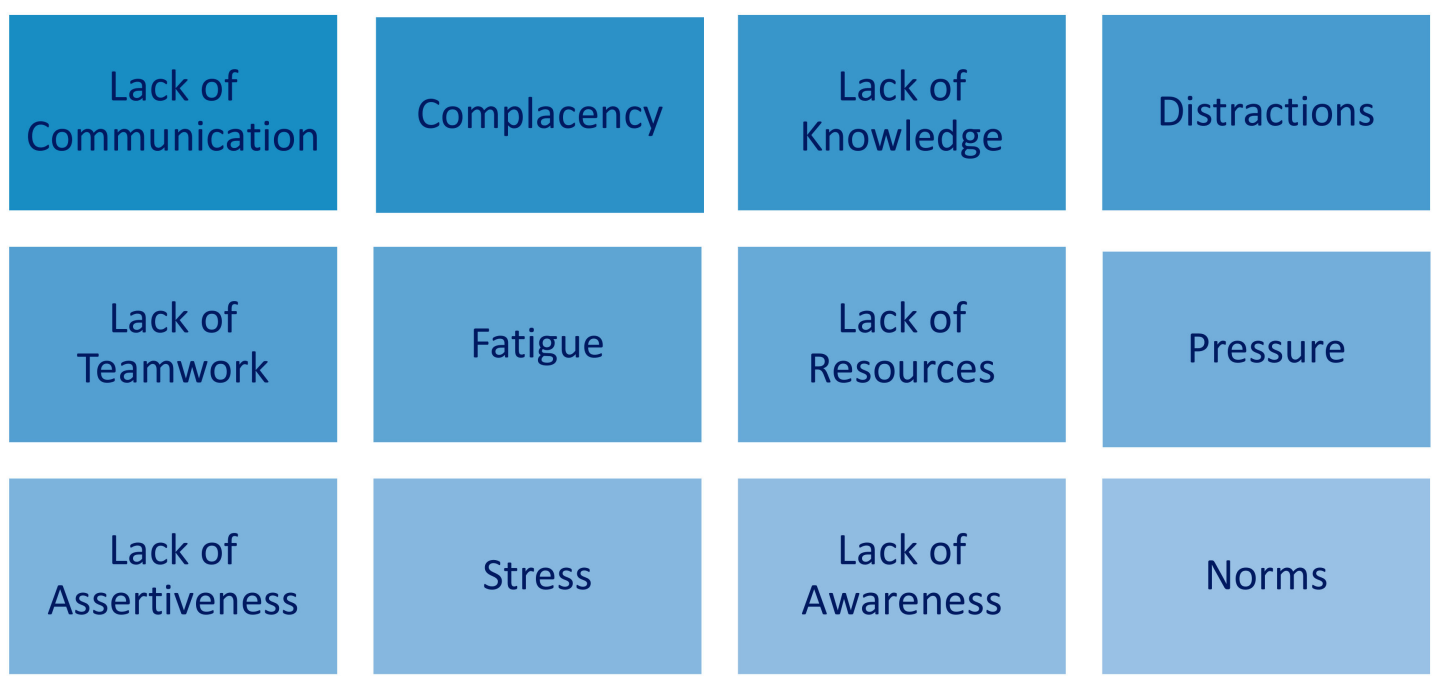

Figure 1. The Dirty Dozen [16].

\section{Basic Communication Theory}

Communication is a field of study that is of interest for many disciplines, such as marketing or computer science. Communication is a process that everyone uses in their everyday life. However, defining communication has proven to be challenging. There have been many definitions of communication in textbooks and different approaches through the years since Shannon and Weaver [23] saw communication as the transmission of messages [24].

There are various definitions of communication depending on the different approaches and discipline of each researcher. In some definitions there is emphasis on the significance of symbols, as in "the transmission of information, ideas, emotions and skills ... by the use of symbols" (Page 527 in [25]), while others examine communication as a product, e.g., "We use the word 'communication' sometimes to refer to what is so transferred, sometimes to the means by which it is transferred, sometimes to the whole process" (Page 13 in [26]). In the study of communication there are two main streams. One stream considers communication as the transmission of messages and the other as the production and exchange of meaning [24].

At the transmission of the message stream, the member that sends the message is the sender, and the one who accepts it is the receiver. Communication, to be effective, must be an active process where both 
the sender and the receiver/s assure that the intended objectives are met. To achieve that, both the coding and the decoding process of the message along with the channel and/or medium of communication, are very important to success. If the result is not the anticipated, then the communication process is characterized as failed and the communication steps are investigated to identify the causes of this failure [24]. The second stream, the production and exchange of meanings deals with the interaction between messages and people and the meaning that comes out of this interaction. In this stream, connotation is a term that is usually met. Additionally, misunderstandings, besides being a result of failure in communication, may occur due to cultural differences between the sender and the receiver [24].

According to Schramm [27] important elements that should be added to the communication process are the sender's and receiver's experiences. The mode of communication chosen should be the appropriate one to meet the circumstances of both the sender and the receiver. The sender proceeds with the message coding based on his/her experience while the receiver understands the message by connecting it to his/her prior knowledge/cognitive level. Then the sender needs to ensure that the message has been transmitted correctly by evaluating the receiver's feedback [27] as shown in Figure 2.

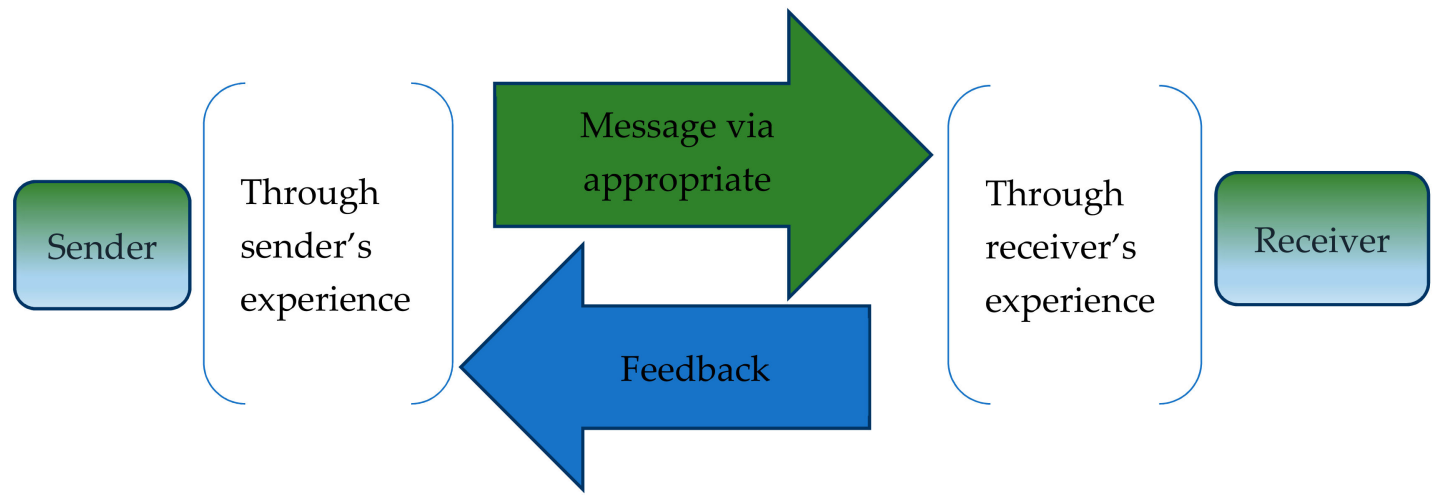

Figure 2. Schramm's [18] communication model with feedback.

To understand the communication theories fully the definitions of the terms: channel, code, and medium are necessary. Channel is the means through which information flows [28]. Examples of channels are: light waves, sound waves, radio waves. Medium is the material or mechanical way of transforming the message into a signal capable of being passed on along the channel. Coding is the sharing of mutual meaning between members of the same culture [24].

The basic features of the chosen channel determine the nature of the medium that will be selected. Next, this medium will determine the characteristics and the range of the codes that will be used to transmit the message. Fiske [24] further suggests that media can be divided into three categories as shown in Figure 3:

a. The presentational media. The body language, the oral speech, the facial expressions are providing communication. This requires the physical presence of the communicator as he/she is the medium and communication happens in real-time.

b. The representational media. Any medium that represents the above by the production of a text, picture, painting, piece of art. These media do not require the presence of the communicator as they can act independently.

c. The mechanical media. These media utilize technologically developed channels; therefore, they are transmitters of the presentation and representation media. Examples are: radio, television, computers, and telephones.

Given that communication is effective and complete it can (a) be beneficial to staff's interpersonal and group relationships; (b) guarantee that attitudes and expectations will be clear with no hidden agendas; (c) retain focus on the task and situational awareness; and (d) act as a managing tool [29]. 


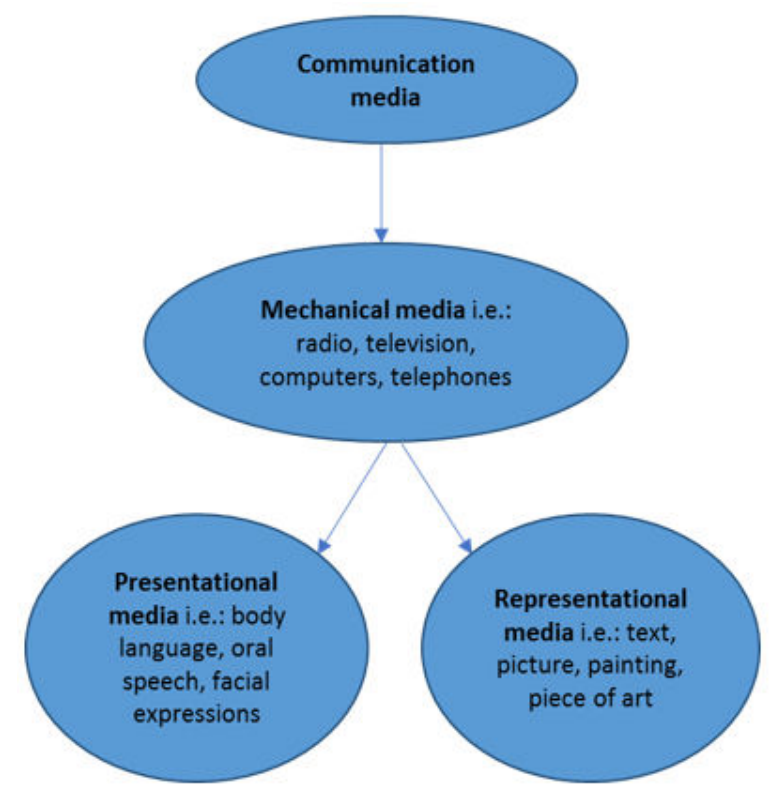

Figure 3. Concept map of communication media.

\subsection{Miscommunication}

To understand and define communication, researchers needed to clarify miscommunication as well. Communication and miscommunication are strongly interrelated, and they present a difficulty in investigating them separately. Miscommunication is treated as a kind of communication with its own distinct patterns and characteristics [30]. In this context miscommunication can be defined as 'the dark side of interpersonal communication' [31] not being too far from its standard meaning of missing, flawed, and disrupted rules of communication [32].

Furthermore, miscommunication includes 'mismatching interpretation' and distortion of message [30]. This definition also includes the potential cultural differences between the sender and the receiver which are responsible for possible alternative interpretative models. Miscommunication, in the condition that if it is noticed and attempted to be repaired, has positive outcome to the communication process as well as it provides a chance for further interaction between the communicators. Miscommunication has been included in several communication theories, e.g., Shannon and Weaver [23], through the years as a deviation or a disruption, either important or less important, at any stage of the communication process [30].

In the aircraft maintenance environment, a model of communication fault was developed by Shukri, Millar, Gratton and Garner [33] that was inspired by Cushing's [34] detailed overview of communication failures between pilot and a traffic controller. In this model there are six message characterisations: "(a) A message that is unavailable; (b) A message that is available but incomplete; (c) A message that is available, complete but incorrect; (d) A message that is available, complete, correct but not clear; (e) A message that is available, complete, correct, clear but not understood; and (f) A message that is available, complete, correct, clear, understood but mistakes still happen due to human factors" [33].

From this model, it is evident that even if the message is free from all the failure prone factors, there is still the possibility of mistakes. Subsequently, all the specialists' efforts lead to the direction of the elimination of the known or predictable factors that can lead to fault and the constant attempt to identify and eliminate the uncharted ones. Therefore, in the case that communication for one or more reasons does not result in the correct exchange of the message, the beneficial effects are not fully realised.

The contribution of communication to the occurrence of human errors has been recorded in various reports. Human error can be tagged as the human causal factor associated with aviation 
accidents' [35] or 'the failure of planned actions to achieve their desired ends-without the intervention of some unforeseeable events' [2]. A study commissioned by the Dutch Aerospace Research Centre (NLR), identified various contributory factors to aircraft accidents, incidents, and errors. In seven ground service providers in the Netherlands both management and operational personnel named the ten most frequent factors that are involved in the cause of mistakes on the ramp (see Figure 4). Poor communication is the second most prevalent factor on that list [36].

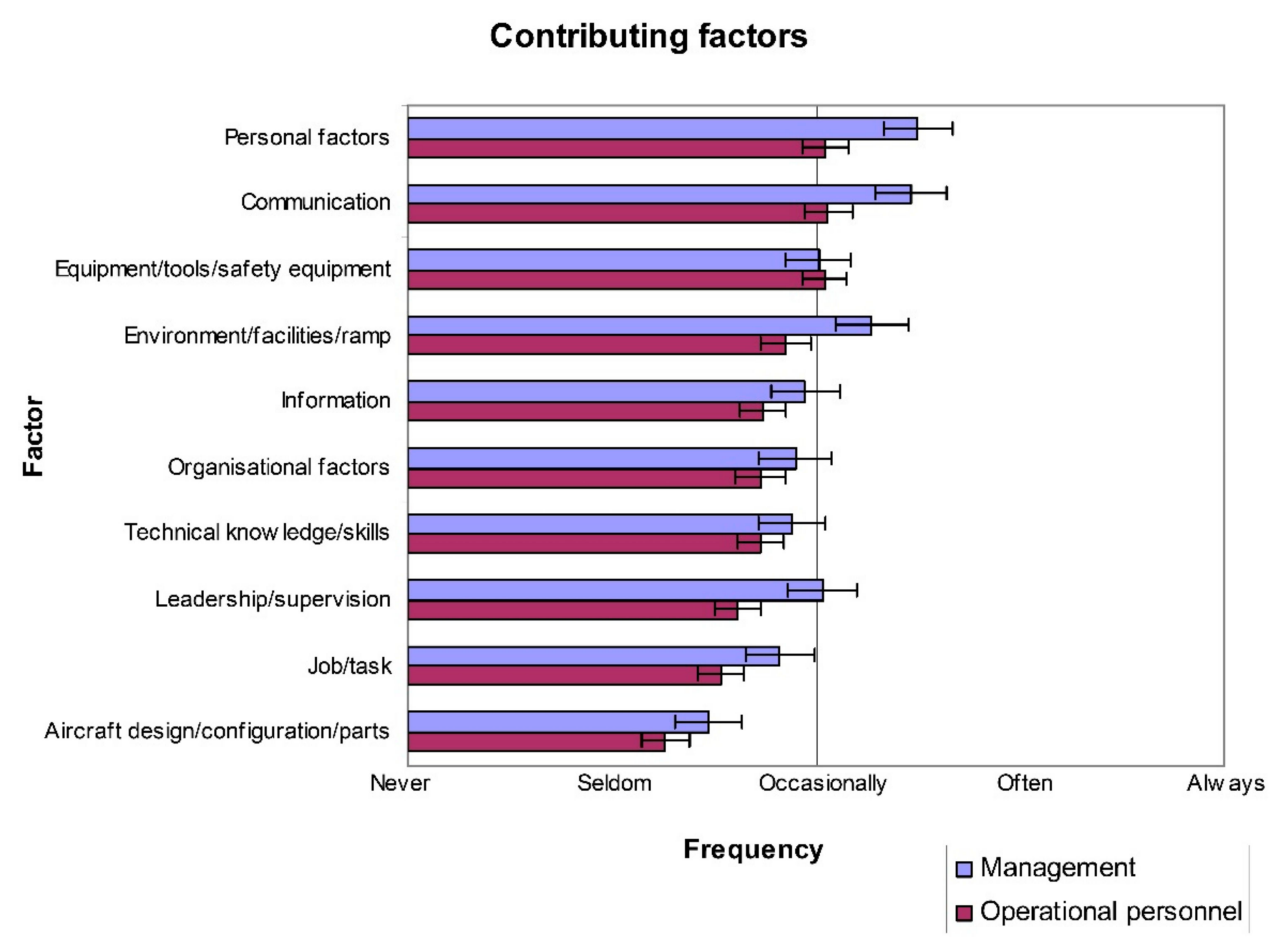

Figure 4. The most frequent causal factors involved in mistakes on the ramp [36].

Ineffective communication is a precondition for human error in all highly complex and regulated industries worldwide [34]. Extended research in aviation has shown that human factors cause 70-80\% of aviation incidents and $15-20 \%$ of them relate to maintenance procedures [37,38]. The aviation sector was the first to identify that the implementation of standardised procedures has contributed to safety and teamwork efficiency, following the realisation that $70 \%$ of commercial flight accidents were caused due to communication errors between crew members [39].

Another large study in the aviation industry found that $70 \%$ of all accidents were caused due to crew coordination and communication issues [40]. These findings are supported by Wiegmann and Shappell [41] and Yacavone [42], as they have recognized crew coordination to be a major contributing factor in military aviation (as cited by Wiegmann and Shappell [43]). Failed communication has also been reported to be among the most frequent local factor in airworthiness events along with tools and equipment, perceived pressure or haste, environment and knowledge, skill, and experience [44]. As a comparison, in railway maintenance, it has been shown that $92 \%$ of incidents occurred due to communication failures $[44,45]$. In the healthcare industry communication is an extremely common element prone to flaws as well [39]. Subsequently, healthcare also had the need for standardization of the communication tools due to its complexity, the limitations of the human performance, and the different training among the medical professionals. For that purpose, tools like SBAR (Situation, Background, Assessment, and Recommendation) were introduced for all medical personnel as a means to establish common terminology and methodology to avoid communication failures [39].

In Figure 4 it is indicated that the management's awareness is at higher levels than the line personnel's, suggesting that the administration has recognised these factors to be preconditions of human errors. The European Commercial Aviation Safety Team (ECAST) has acknowledged the 
awareness of the potential risk of ineffective communication as a human factor and that further research is necessary towards that direction [36]. Moreover, various researchers have highlighted the problem of ineffective communication between maintenance staff, cabin crew, and flight crew, proposing different ways to mitigate this issue $[46,47]$. It is evident from the above that communication is a very important element within complex industries like aviation.

An example, in which maintenance communication was involved in an airplane accident, is the Atlantic Southeast Airlines flight 529 in August 1995. The aircraft crashed in Georgia, USA, during an emergency landing, after the loss of a propeller blade, resulting in 9 fatalities and 20 injuries. The National Transportation Safety Board (NTSB) determined that "the probable cause of this accident was the in-flight fatigue fracture and separation of a propeller blade resulting in distortion of the left engine nacelle, causing excessive drag, loss of wing lift, and reduced directional control of the airplane. The fracture was caused by a fatigue crack from multiple corrosion pits that were not discovered by Hamilton Standard because of inadequate and ineffective corporate inspection and repair techniques, training, documentation, and communications." [48]. The NTSB in this report highlighted as a contributing factor the internal inadequate communication and documentation systems of the airplane parts' manufacturer that led maintenance personnel to confusion and faulty procedures.

Even though aviation was the first industry to regulate and implement human factors policies and guidelines, the need for further research and procedural improvement is continuous and arduous. In the occurrence of any new procedure introduced, new research over the possible reasons for failure of the system or its human element towards its failure must be conducted. Moreover, the continuous effort to make communication in aviation effective has led to the observation and understanding of all aspects of human expressions. Different modes of expression, such as politeness [49], are under review by human factors specialists, in their attempt to promote clarity and minimize miscommunication at all levels.

\subsection{Areas in Aviation Maintenance Prone to Communication Failure}

In aviation maintenance one critical aspect is documentation. The most common reason for accidents in aviation maintenance is insufficient documentation and procedures [50-52]. More recent studies indicate that written communication can be more prone to mistakes than oral communication during critical maintenance tasks. The reason is that in oral communication any clarification is easier to obtain, so more human errors, that affect aircraft safety, are detected [33].

The improvement of maintenance documentation can establish communication as an important factor that could have a positive contribution to the execution of maintenance tasks safely [50,53]. Written procedures govern every action in aircraft maintenance. These are manufacturers' Instructions for Continued Airworthiness (ICA's), Fault Isolation Manuals and all supporting documentation that are continually updated. Additionally, as aircraft design is evolving fast and becoming more sophisticated, maintenance-related information is expanding in volume. This immense amount of documentation amendments and novelty has to be adopted simultaneously by maintenance personnel around the world, even if their first language is not the one the documentation was produced in $[54,55]$.

Moreover, there is extended research in the development and improvement of online platforms, that aim to replace workcards, targeting lower cost along with a positive impact on the engineers' situational awareness, error probability, job satisfaction, and adaptability [56,57]. Another example is that of a Federal Aviation Administration (FAA) three-phase sponsored study that dealt with an improved design of the manufacturer's maintenance documentation enabling the transfer of information to the maintenance personnel at a satisfactory level [58].

Many researchers have produced instructions and guidelines, following human factors principles, to help maintenance staff avoid mistakes. Their research has been successful in reducing human errors [55,59]. However, the people in charge do not always acknowledge this work by implementing it in the field [60]. They usually persist in following their own former good experience and the employees' perspective rather than adopt guidelines and instructions that stem from research [58]. 
Moreover, shift turnover is of great significance in highly complex and regulated business environments, such as aviation maintenance, the oil industry, and medicine. According to Parke and Kanki, from the $8 \%$ of the aircraft maintenance failures that were due to communication factors, $51 \%$ were related to the shift turnover while $41 \%$ had no relation to it [61]. The turnover related maintenance occurrences were classified, by the reporting system used for this research, to have more severe and dangerous consequences [61] whereas debriefs that are conducted according to human factors principles can enhance productivity by 20-25\% [62]. While debriefs may appear to be cost effective and produce quick results in the organizations' improvement of performance, the study of such processes over the years is scattered across different disciplines, such as healthcare, education, psychology, and organizational fields with no conclusive results [62].

The literature highlights that communication in the aircraft maintenance environment provides several considerations: first, it is an element that underlies every phase of the aircraft maintenance process; next, it is a primary element of the maintenance process, as it is the framework upon which information transmission takes place; finally, the research community and the industry need to proceed with further investigation on documentation structure and shift turnover procedures.

\subsection{Communication in Aviation Training}

The training framework in aviation is designed to enhance communication skills and techniques, promote teamwork, accommodate human performance tools and develop situational awareness (SA) among maintenance personnel. This indicates of the way that the aviation industry values communication, acknowledges it as an important contributing factor of human performance and takes actions towards its successful application within the aviation various activities. This training is either called Crew Resource Management (CRM), Maintenance Resource Management (MRM), or Team Resource Management (TRM) [63-65].

As the literature indicates: (a) training is essential in enhancing elements such as successful communication and indeed has good results, and (b) the design of training, the delivery and its implementation is of great importance in achieving the required results in areas such as communication $[50,66,67]$. To define the success of training in promoting factors such as communication, more 'on the job' observation of the participants is needed, given that most of the research has been conducted in simulation $[64,68,69]$.

In the European Union, there is a 30 mil. Euro program (Future Sky Safety 2015-2019) that explores all new tools and approaches to aviation safety. This research, among other issues, indicates that a significant gap has been recognized between the quality of the students' oral and written communication skills gained during their studies (especially in the aeronautical area) and the skills required by the aeronautical industry to perform the tasks safely [70]. Industry and academia do not work together as the communication between them is ineffective and discontinued [71,72]. This indicates that since there is no wide human factors training within the tertiary education curricula, there is a great need for it in newly recruited personnel.

\section{Trust}

First, trust is the belief of somebody else's benignant intentions. Second, none can impose these beliefs to come true, in other words trust means to be prepared for the possibility that the anticipated benignant outcome will not happen. Third, the meaning of trust includes a degree of interdependency as somebody's situation is linked to somebody else's actions [13]. Based on these three elements, trust is the attitude someone or a party adopts (trustor) towards somebody else or another party (trustee) [73]. This attitude, or even both parties' relationship, is influenced by the trustee's behaviour and it will form the trustor's understanding and receptiveness towards the trustee [13]. It is noted in the literature that the competence, benevolence and integrity of the trustee are the characteristics that trustor takes into consideration for the formation of his/her trust $[74,75]$. 
Trust, while it has been extensively researched by organizational researchers and more specifically by certain industries (e.g., web commerce) is understudied in high-reliability organisations, such as the aviation industry [76]. Trust usually stands in combination with other human characteristics and is difficult to be isolated and quantified. However, there is growing research indicating that trust and professionalism are fundamental factors in maintaining safety in the aviation industry. On the one hand, professionalism is the basis to exercise all the necessary steps towards safety, but on the other hand, personal trust is essential in the communication that is required $[19,20,22,77,78]$.

Additionally, personal trust is associated with performance and cooperation [79-82], citizenship behavior [83], problem solving [84], and confidence in the skills and capabilities of aviation experts (trust in competence), to achieve the desired level of safety [85]. Maintenance personnel need to trust that their colleagues will act as safely as themselves. This is a process that needs to be inspired and enhanced rather than taken for granted [86].

Trust towards people, and especially towards individuals in the case of a risky situation, where an individual will do anything within his/her power to overcome the risk, aspires to be a solid factor in ensuring safety management [85]. However, Harvey and Stanton [85] and Reason [87] argue that this statement contradicts the modern systems approach to risk and human error, according to the human factors principles, as human error has been considered so far to be a systemic rather than an individual consequence $[88,89]$. Adaptation is inevitable where models include the social system and human error while organizations put pressure on their systems on the benefit of their cost effectiveness-productivity balance [90].

Apart from the trust between colleagues, there is the trust between maintenance personnel and management that has been rather low and makes staff feel sceptic and pessimistic whether positive results in safety can be achievable [65]. Management is responsible for building (establishing/taking the initiative towards the employees) and maintaining trust [13]. Apart from the interpersonal trust, there is the confidence towards technology and procedures. Additionally, another characteristic of trust is that it is bipolar: lingering between the two edges of trust and distrust [91,92].

Procedures are clusters of partial steps that, to be successful, need to meet different criteria and conditions (e.g., environment). Due to different reasons (e.g., lack of knowledge, norms) maintenance employees might not take these conditions under consideration in the case of failure. Situations like these might lead these professionals to lose trust in procedures, in the case of a failure, or show overreliance in the instance that the procedures were effective even if the right conditions were not met [92].

The benefits of trust have been well understood for some decades now since Zand proved in 1972 [84] that employees with higher levels of trust compared to the ones with lower levels: (a) make information processing more cost-effective to the company; (b) seem to have more contentment among them; and (c) show certainty towards other counterparts [84]. Research has also shown that trust towards familiar individuals is far more easily achieved, especially when positive feedback indicates this person to be trustworthy. Obviously, the level of trust tends to differ amongst various organizations, depending on their size. In small organizations, the interpersonal trust seems to be at a higher level than in larger organizations and the army [93].

Technology, on the other hand, is a human construction and, as a product, it lacks human characteristics [94]. To focus on the technology, one should isolate it from the human element (users, developers) and examine the technology artifact itself. This approach enables the investigation of trust towards technology without being influenced by other surrounding human structures [95].

People depend on technological artifacts and rely on their anticipated abilities and capabilities to perform successfully. In this concept trust means to depend or rely on another [96]. Therefore, if someone believes he/she can depend on technology's performance in a time of need, then trust towards technology is the describing term for it [95].

Trust in technology is divided into initial trust and knowledge-based trust [95]. Initial trust refers to the expectations and beliefs of the anticipated operations of the technological application chosen by 
the user. Knowledge-based trust is the result after interaction and familiarization with a technological system. Trust in technology needs further investigation as limited research has been conducted in this area [95].

Furthermore, in modern times, more organisations have evolved into big impersonal enterprises where trust between groups is difficult to achieve [15]. To overcome this issue, organisations have to agree, adopt and utilise similar social rules to gain familiarity and work together efficiently [97]. Even though these sets of rules seem to prevent distrust among enterprises, some researchers insist that interpersonal relations are the ones that guarantee the formation of trust. This means that specific people need to represent organisations to form the needed familiarity [98].

Within business relations, trust is a fundamental factor that takes part in the orchestration of their expectations and mode of collaboration [99]. It appears to have an assistive role in establishing business relationships and it is crucial to re-establish the theory behind the organisational influences on the business behaviour. This will be of major help in attempts at building trust in interorganisational interactions [15]; "The more complex and dynamic social and economic relations and exchange arrangements are today, the more trust is needed as a lubricant to keep the motor running" [100].

Overreliance or excessive trust may have negative effects on interpersonal and organizational relations and there is no current research to describe it adequately [101]. To unfold the role that trust plays in organizations, one must explore the macrolevel and microlevel of theory and analysis. In the macro level, trust is studied regarding its interaction with the industry structure while in micro level trust is examined among people as seen in Figure 5 [102].

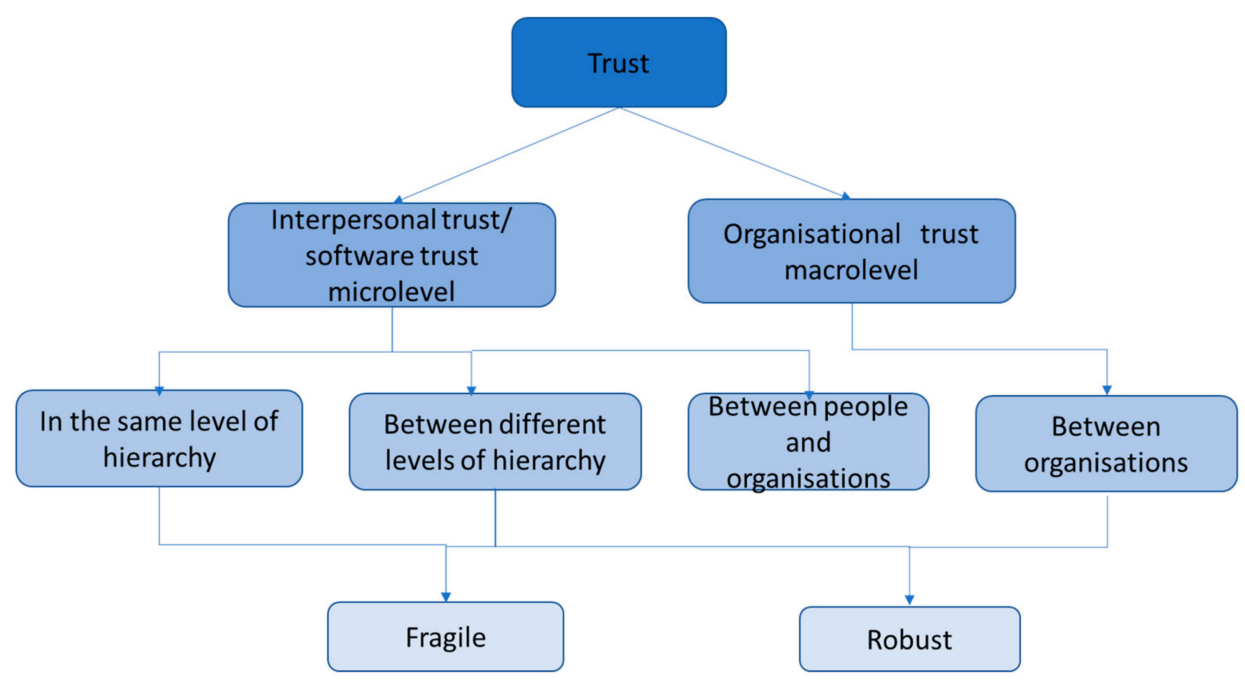

Figure 5. Schematic representation of the concept of trust [102].

\subsection{Trust Dynamics within the Organization}

When systems in organizations promote open and free communication (knowledge sharing, uninhibited information disclosure) their employees are more likely to develop trust towards the organization and each other $[13,74,101]$. From the very beginning, trust has been linked to safety in the aviation industry and there has been a significant effort through MRM training (5th generation) to implement and enhance safety culture and engage all personnel in that direction.

In the case that an organization proceeds with implementing all necessary actions to reduce human errors then learning from their mistakes would be one of them. In this case, it is crucial to the people involved to have sufficient trust that they will not be blamed if they report mistakes and that they can speak openly about them (commonly called a just culture $[103,104])$. Although there are mechanisms available to maintenance personnel to avoid or reduce human errors, they must trust their managers mutually to achieve that. 
Studies have revealed that a big proportion of engineers do not trust that their managers' actions will be solely aimed at enhancing safety [105]. The lack of trust, or distrust, acts as an obstacle to the formation and implementation of programs, such as the FAA's Aviation Safety Action Program (ASAP), that provides maintenance personnel with a system to report failures and thereby contribute to the continuous effort to improve aviation safety.

\subsection{Characteristics of Trust}

Other extended research on trust indicates that trust is at high levels at the beginning of a professional relationship "high initial trust levels" [106]. New employees begin their employment with an intrinsic level of trust towards their colleagues and their organizations. Thereafter, it is the culture of each organization that will be responsible for maintaining or altering this level. Trust is also a multidimensional area that is highly influenced by other social features. As proposed in the Model of Trust by Mayer, Davis, and Schoorman (as cited by Mayer et.al. [75]) trustworthiness is perceived by factors like ability, benevolence and integrity. In a society that is trained to believe and rely on others, it is most probable that people will trust their organization initially at a high level $[106,107]$.

Depending on the circumstances, trust levels can appear to develop as fragile or robust. Fragile is when it is subject to sudden changes during a given period either to a higher level, when the initial level is low or vice versa. Robust, on the other hand, is the opposite of fragile. It is used when the level of trust remains stable over a specified period [106]. Since the existence of the "high initial trust levels" is observed, it is of primary importance in the aviation industry to maintain it at those levels. It will only be successful by keeping in mind that the elements that make trust robust are: (a) adequate precedent support, that is former good experience which forms a present behaviour in a similar manner; (b) belief-confirming cognitive mechanisms, in which people's remarks that oppose their beliefs are overlooked; and (c) social mechanisms, the personal contact among people enhances the positive attitude between them [106]. Moreover, research has identified legislative procedures, conflicts of power, stress, and liability to be factors that reduce trust within organisations [108,109].

Furthermore, research has confirmed the relationship between ASAPs and trust since organizations with ASAPs in place have demonstrated higher scores in trust than other companies in which ASAPs were not in their structure [110]. To evaluate the personal perception of maintenance personnel regarding human factors and safety in the workplace, specific tools had to be introduced. One tool that has been extensively used by FAA is the Maintenance Resource Management Technical Operations Questionnaire (MRM/TOQ). Among other questions that were used to measure different human factors, the following questions were used to measure the level of trust:

- "My supervisor can be trusted".

- "My safety ideas would be acted on if reported to supervisor".

- "My supervisor protects confidential information."

- " "I know proper channels to report safety issues" [86,110].

These types of questionnaires evolve and adapt over time, and new data is accumulating through continuous research. The optimum result would be to obtain a large amount of data from the full range of aviation activities, which would enable researchers to analyse results comparatively, inferentially, and longitudinally [86].

\section{The Relation between Trust and Communication}

Literature has indicated that personal trust is an essential element that is associated with successful communication (see, for example, $[15,16,18-20,22,77,78]$ ). Experimental research has proven that face-to-face communication has been highly successful due to, among other reasons, the lifting of anonymity and the trust that the communicators show to each other. Face-to-face communication enhances verbal communication where trust elements, such as commitment and promises, are used along with body language, facial expressions, and visual cues to ensure a successful outcome [82]. 
Experimental evidence, regarding the relation between trust and communication, is scarce and more research in that field is needed [82].

When it comes to group communication, the group should establish common ground for the members to agree upon some basic ideas/concepts. This process depends on trust development among the members, towards their incentives and attitudes, for the group to create a functioning communication ([30] as adapted by $[111,112])$.

At the organizational level, when organizational culture supports open and free communication among all levels of employees, it is expected from them to enhance their trust levels towards each other and their organization $[13,74,101]$. Recent research in the aviation maintenance field indicated that communication and trust are two major factors that both can be used as tools for maintenance failure detection [113]. Additionally, according to the FAA, trust is an essential element for a successful safety program in the aviation industry. The different safety programs base their effectiveness on the successful communication among the different business partners and mutual trust or distrust can affect this communication.

\section{Discussion and Conclusions}

This review aimed to include mainly aviation maintenance literature relevant to communication and trust and this literature was found to be scarce. This suggests that, the factors of communication and trust, either individually or in combination, are understudied in aviation maintenance. To unfold this critical issue, communication and trust were explored in multidisciplinary literature and they were considered within the aviation maintenance framework. Some of the most important findings of the review are presented in Figure 6.

Most researchers have concluded that aviation has recognised miscommunication as a paramount human factor contributing to errors [36,114], but there is still much work to be done to eliminate this risk and provide the industry with error free communication. A gap has been identified in the issues that arise from the communication among different areas within aviation, and there is research underway mitigating these issues $[46,47]$. Every aspect of human nature and personality characteristics should be considered, to eliminate the factors that might lead the message to not be adequately delivered and understood in the communication process. To succeed in this, it is of high importance to place the mechanisms and models of miscommunication in the specific frame of aviation industry [30] as there is a great deal of potential in their implementation and development, especially in aviation maintenance [115].

Several decades ago, it became quite apparent that standard terminology and methodology would help reduce human errors related to aircraft procedures, especially in the written forms of communication, e.g., documentation, manuals, workcards, etc. [55,59]. Due to such endeavours, new technology and improved software are being used in the place of internal communication forms and workcards with encouraging results [56,57]. Extended research has still to be conducted in this direction to make novel technology more appealing and subsequently resolve both managers' and employees' negative attitude to similar platforms [58]. On the other hand, there is a lack of systemic study of maintenance debriefings that does not help in the comprehension and improvement of this crucial step in the maintenance procedure [62].

Training is the only vehicle that will introduce and facilitate all the required communication skills [63-65,116]. There has been considerable research during the past few decades in developing systems and the generation of effective programs. There is, however, potential for further research in the long-term effectiveness of these programs as trainees do not seem to acquire the desired level of knowledge and skill [50].

The framework within interorganisational trust has a lot of potential to be restructured, to enhance business interactions, and to achieve further development [15]. The literature found that deals with trust in the aviation industry is scarce. This alone indicates that there is a great deal of work that could be done in identifying and associating trust with other traits in the actual working environment in 
aviation maintenance [19]. The interesting element in trust is that the initial levels of trust (the levels of trust an individual or a company indicates at the beginning of a collaboration) are high, so human factors researchers could focus their research towards the direction of the mechanisms which will contribute to maintaining these levels high over time [106].

Experimental evidence, regarding the relation between trust and communication, is scarce and more research on that field is needed [82].

More specifically the relationship between trust and communication (how they interact with each other) among colleagues, between subordinates and managers/supervisors and between maintenance staff and technology.

$$
\text { Communication }
$$

Most researchers have concluded that aviation has recognised miscommunication as a paramount human factor contributing to errors $[36,114]$, but there is still much work to be done to eliminate this risk and provide the industry with an error free communication

To succeed in this, it is of high importance to place the mechanisms and models of miscommunication in the specific frame of aviation industry [30] as there is a lot of potential in their implementation and development there, especially in aviation maintenance [115].

While debriefs may appear to be cost effective and produce quick results in the organizations' improvement of performance, the study of such processes over the years is scattered across different disciplines with no conclusive results [62].

This research, among other issues, indicates that a significant gap has been recognized between the quality of the students' oral and written communication skills gained during their studies (especially in the aeronautical area) and the skills required by the aeronautical industry to perform the tasks safely [71].

Extended research has still to be conducted in using new technologies to make them more appealing and subsequently resolve both managers' and employees' negative attitude to similar platforms [58].

Trust, while it has been extensively researched by organizational researchers and more specifically by certain industries (e.g. web commerce) it is understudied in high-reliability organisations, as the aviation industry [76] .

The optimum result would be to obtain a large amount of data from the full range of aviation activities, which would enable researchers to analyze results comparatively, inferentially, and longitudinally [86].

The literature found that is dealing with trust in the aviation industry is scarce. This alone indicates that there is a lot of work that could be done in identifying and associating trust with other traits in the actual working environment in aviation maintenance [19].

The interesting element in trust is that the Initial levels of trust (the levels of trust an individual or a company indicates at the beginning of a collaboration) are high, so human factors researchers could focus their research towards the direction of the mechanisms which will contribute to maintaining these levels high over time [106].

More extensive research is needed to standardize trust measuring methodologies, in analyzing the results, and to enable smaller scale research to be compared safely, which in turn will lead to reliable results and interventions [86]. Only over recent years, have researchers started trying to unveil the causational factors for maintenance errors [117].

Trust in technology and the negative effects of excessive interpersonal or organizational trust can be researched further, as again these are understudied fields, especially in aviation maintenance.

Figure 6. Tabular representation of the recognised future research potentials. 
More extensive research is needed to standardize trust measuring methodologies, analyse results, and enable smaller-scale research to be compared safely, which, in turn, will lead to reliable results and interventions [86]. Only over recent years have researchers started trying to unveil the causal factors for maintenance errors [117].

Following the example of 'Future Sky Safety' and trying to fill in the gap of the human factors research in aviation maintenance, the investigation of the interaction between two factors, such as communication and trust, is pioneering within the aviation maintenance context and of great importance. The research that has been conducted in aviation human factors so far is mainly a single factor research. Therefore, the study of two and more factors and their impact on human performance is a direction more researchers should follow in the future, given that human reaction is the result of different factors and conditions that interact with each other.

Under the scope of the investigation of factors in combinations, it would be interesting to see further combined research in communication and trust in aviation maintenance. More specifically the relationship between trust and communication (how they interact with each other) among colleagues, between subordinates and managers/supervisors, and between maintenance staff and technology. Furthermore, trust among aviation businesses and how they interact with each other would be a domain for further research, as new data could be exposed. Moreover, trust in technology has been under-researched in the aviation maintenance domain, which appears to be bereft of any significant research in this field. Additionally, the negative effects of excessive interpersonal or organizational trust can be researched further as, again, this is an understudied field, especially in aviation maintenance.

Author Contributions: Conceptualization, A.V.C.; Data Curation, A.V.C.; Writing-Original Draft Preparation, A.V.C.; Writing-Review \& Editing, A.V.C., W.M., P.B., P.M.

Funding: This research received no external funding.

Conflicts of Interest: The authors declare no conflict of interest.

\section{References}

1. Dhillon, B.S.; Liu, Y. Human Error in Maintenance: A Review. J. Qual. Maint. Eng. 2006, 12, 21-36. [CrossRef]

2. Reason, J.T. Managing the Risks of Organizational Accidents; Ashgate: Farnham, UK, 1997.

3. European Aviation Safety Agency. Annual Safety Review 2014; European Aviation Safety Agency: Cologne, Germany, 2015.

4. Blaise, J.-C.; Levrat, E.; Iung, B. Process Approach-Based Methodology for Safe Maintenance Operation: From Concepts to SPRIMI Software Prototype. Saf. Sci. 2014, 70, 99-113. [CrossRef]

5. Chang, Y.-H.; Wang, Y.-C. Significant Human Risk Factors in Aircraft Maintenance Technicians. Saf. Sci. 2010, 48, 54-62. [CrossRef]

6. Dupont, G. The Dirty Dozen Errors in Maintenance. In Proceedings of the 11th Symposium on Human Factors in Maintenance and Inspection: Human Error in Aviation Maintenance, Washington, DC, USA, 12-13 March 1997.

7. Flin, R.; O'Connor, P.; Mearns, K. Crew Resource Management: Improving Team Work in High Reliability Industries. Team Perform. Manag. Int. J. 2002, 8, 68-78. [CrossRef]

8. Marquardt, N.; Gades, R.; Robelski, S. Implicit Social Cognition and Safety Culture. Hum. Factors Ergon. Manuf. Serv. Ind. 2012, 22, 213-234. [CrossRef]

9. Wise, J.A.; Hopkin, V.D.; Garland, D.J. Handbook of Aviation Human Factors; CRC Press: Boca Raton, FL, USA, 2010.

10. Reiman, T. Understanding Maintenance Work in Safety-Critical Organisations-Managing the Performance Variability. Theor. Issues Ergon. Sci. 2011, 12, 339-366. [CrossRef]

11. Federal Aviation Administration. Addendum-Chapter 14: Human Factors. In Aviation Maintenance Technical Handbook FAA-H-8083-30; US Department of Transportation: Oklahoma City, OK, USA, 2011.

12. Silvagni, S.; Napoletano, L.; Graziani, I.; Blaye, P.L.; Rognin, L. Concept for Human Performance Envelope; EU Horizon 2020 Research and Innovation Programme: Brussels, Belgium, 2015. 
13. Whitener, E.M.; Brodt, S.E.; Korsgaard, M.A.; Werner, J.M. Managers as Initiators of Trust: An Exchange Relationship Framework for Understanding Managerial Trustworthy Behavior. Acad. Manag. Rev. 1998, 23, 513-530. [CrossRef]

14. Hernandez, J.M.d.C.; Santos, C.C.d. Development-Based Trust: Proposing and Validating a New Trust Measurement Model for Buyer-Seller Relationships. BAR Braz. Adm. Rev. 2010, 7, 172-197. [CrossRef]

15. Bachmann, R. The Coordination of Relations Across Organizational Boundaries. Int. Stud. Manag. Org. 2003, 33, 7-21. [CrossRef]

16. Carrière, J.; Bourque, C. The Effects of Organizational Communication on Job Satisfaction and Organizational Commitment in a Land Ambulance Service and the Mediating Role of Communication Satisfaction. Career Dev. Int. 2009, 14, 29-49. [CrossRef]

17. Cascio, W.F. Managing a Virtual Workplace. Acad. Manag. Exec. 2000, 14, 81-90. [CrossRef]

18. Cho, Y.J.; Park, H. Exploring the Relationships Among Trust, Employee Satisfaction, and Organizational Commitment. Public Manag. Rev. 2011, 13, 551-573. [CrossRef]

19. Flin, R. Measuring Safety Culture in Healthcare: A Case for Accurate Diagnosis. Saf. Sci. 2007, 45, 653-667. [CrossRef]

20. Muchinsky, P.M. An Intraorganizational Analysis of the Roberts and O'Reilly Organizational Communication Questionnaire. J. Appl. Psychol. 1977, 62, 184-188. [CrossRef]

21. Shapiro, D.B.; Sheppard, H.; Cheraskin, L. Business on a Handshake. Negot. J. 1992, 8, 365-377. [CrossRef]

22. Yeager, S.J. Measurement of Independent Variables Which Affect Communication: A Replication of Roberts and O'Reilly. Psychol. Rep. 1978, 43, 1319-1324. [CrossRef]

23. Shannon, C.; Weaver, W. The Mathematical Theory of Communication; University of Illinois Press: Champaign, IL, USA, 1949.

24. Fiske, J. Introduction to Communication Studies (Studies in Culture and Communication); Taylor \& Francis Group/Books: London, UK, 1990.

25. Berelson, B.; Steiner, G. Human Behavior: An Inventory of Scientific Findings; Harcourt, Brace, and World: Oxford, UK, 1964; p. 527.

26. Ayer, A.J. What is Communication? J. Commun. 1955, 9, 13.

27. Schramm, W. How Communication Works. In The Process and Effects of Mass Communication; University of Illinois Press: Champaign, IL, USA, 1954; pp. 3-26.

28. Duncan, T.; Moriarty, S.E. A Communication-Based Marketing Model for Managing Relationships. J. Mark. 1998, 62, 1-13. [CrossRef]

29. Kanki, B.G.; Helmreich, R.L.; Anca, J. Communication and Crew Resource Management. In Crew Resource Management, 2nd ed.; Academic Press: London, UK, 2010; pp. 111-146.

30. Anolli, L.; Ciceri, R.; Riva, G. Say not to Say: New Perspectives on Miscommunication; IOS Press: Washington, DC, USA, 2002; Volume 3.

31. Parret, H. Indirection, Manipulation and Seduction in Discourse. In Pretending to Communicate; Walter De Gruyter GmbH: Berlin, Germany, 1994.

32. Mortensen, C.D. Miscommunication, 1st ed.; Oaks, T., Ed.; Sage Publications: London, UK, 1997.

33. Shukri, S.A.; Millar, R.M.; Gratton, G.; Garner, M. The Potential Risk of Communication Media in Conveying Critical Information in the Aircraft Maintenance Organisation: A Case Study. IOP Conf. Ser. Mater. Sci. Eng. 2016, 152, 012044. [CrossRef]

34. Cushing, S. Fatal Words: Communication Clashes and Aircraft Crashes; University of Chicago Press: Chicago, IL, USA, 1994.

35. Dismukes, R.K. (Ed.) Human Error in Aviation; Routledge: London, UK, 2009.

36. Balk, A.D.; Bossenbroek, J.W. Aircraft Ground Handling and Human Factors. A Comparative Study of the Perceptions by Ramp Staff and Management; NLR Air Transport Safety Institute: Amsterdam, The Netherlands, 2010.

37. Drury, C.G. Human Factors in Aircraft Maintenance; RTO AVT Lecture Series: Sofia, Boulgaria, 2000; pp. 15-1-15-9.

38. McFadden, K.L.; Towell, E.R. Aviation Human Factors: A Framework for the New Millennium. J. Air Transp. Manag. 1999, 5, 177-184. [CrossRef]

39. Graham, S.; Bonacum, D.; Leonard, M. The Human Factor: The Critical Importance of Effective Teamwork and Communication in Providing Safe Care. Qual. Saf. Health Care 2004, 13, 85-90. 
40. Lautman, L.; Gallimore, P. Control Caused Accident: Results of a 12-Operator Survey; Boeing Commercial Airplane Co.: Seattle, WA, USA, 1987.

41. Wiegmann, D.A.; Shappell, S.A. Human Error and Crew Resource Management Failures in Naval Aviation Mishaps: A Review of US Naval Safety Cetre Data, 1990-1996. Aviat. Space Environ. Med. 1999, 70, 1147-1151. [PubMed]

42. Yacavone, D.W. Mishap Trends and Cause Factors in Naval Aviation: A Review of Naval Safety Center data. Aviat. Space Environ. Med. 1993, 64, 392-395.

43. Wiegmann, D.A.; Shappell, S.A. A Human Error Approach to Aviation Accident Analysis: The Human Factors Analysis and Classification System; Burlington, V.T., Ed.; Ashgate: Aldershot, UK, 2003.

44. Murphy, P. The Role of Communications in Accidents and Incidents during Rail Possessions. In Engineering Psychology and Cognitive Ergonomics Volume Five Aerospace and Transportation Systems; Harris, D., Ed.; Ashgate: Aldershot, UK, 2001.

45. Rail Safety Standards Board. Railway Group Safety Plan; Rail Safety Standards Board: London, UK, 2003.

46. Caldwell, J.A. Fatigue in Aviation. Trav. Med. Infect. Dis. 2005, 3, 85-96. [CrossRef] [PubMed]

47. Mattson, M.; Petrin, D.A.; Young, J.P. Integrating Safety in the Aviation System: Interdepartmental Training for Pilots and Maintenance Technicians. J. Air Transp. World Wide 2001, 6, 37-64.

48. National Transportation Safety Board (NTSB). Aircraft Accident Report-In-Flight Loss of Propeller Blade Forced Landing and Collision with Terrain, Atlantic Southeast Airlines, Inc., Flight 529, Embraer EMB-120RT, N256AS; NTSB: Washington, DC, USA, 1996.

49. Bonnefon, J.F.; Feeney, A.; De Neys, W. The Risk of Polite Misunderstandings. Curr. Dir. Psychol. Sci. 2011, 20, 321-324. [CrossRef]

50. Taylor, J.C.; Thomas, R.L., III. Written Communication Practices as Impacted by a Maintenance Resource Management Training Intervention. J. Air Transp. 2003, 8, 69-90.

51. Von Thaden, T.L.; Wiegmann, D.A.; Shappell, S.A. Organizational Factors in Commercial Aviation Accidents. Int. J. Aviat. Psychol. 2006, 16, 239-261. [CrossRef]

52. Ward, M.E.; McDonald, N.; Morrison, R.; Gaynor, D.; Nugent, T. A Performance Improvement Case Study in Aircraft Maintenance and Its Implications for Hazard Identification. Ergonomics 2010, 53, 247-267. [CrossRef]

53. Sogg, S. An Integrated Systems Approach to Human Factors in Commercial Aviation Maintenance Systems; Aviation Maintenance Symposium: San Francisco, CA, USA, 2002.

54. Drury, C.G.; Guy, K.P.; Wenner, C.A. Outsourcing Aviation Maintenance: Human Factors Implications, Specifically for Communications. Int. J. Aviat. Psychol. 2010, 20, 124-143. [CrossRef]

55. Drury, C.G.; Johnson, W.B. Writing Aviation Maintenance Procedures That People Can/Will Follow. In Proceedings of the Human Factors and Ergonomics Soiety 57th Annual Meeting, San Diego, CA, USA, 3 October 2013.

56. Kraus, D.C.; Gramopadhye, A.K. Effect of Team Training on Aircraft Maintenance Technicians: Computer-Based Training Versus Instructor-Based Training. Int. J. Ind. Ergon. 2001, 27, 141-157. [CrossRef]

57. Liang, G.-F.; Lin, J.-T.; Hwang, S.-L.; Wang, E.M.-Y.; Patterson, P. Preventing Human Errors in Aviation Maintenance Using an On-Line Maintenance Assistance Platform. Int. J. Ind. Ergon. 2010, 40, 356-367. [CrossRef]

58. Chaparro, A.; Groff, L.S. Human Factors Survey of Aviation Maintenance Technical Manuals. In 16th Human Factors in Aviation Maintenance Symposium; Embry-Riddle Aeronautical University Scholarly Commons: San Francisco, CA, USA, 2002.

59. Chervak, S.; Drury, C.G.; Ouellette, J.P. Simplified English for Aircraft Workcards. Hum. Factors Ergon. Soc. Annu. Meet. Proc. 1996, 40, 303-307. [CrossRef]

60. Karanikas, N.; Soltani, P.; Boer, R.J.; Roelen, A.L.C. Safety Culture Development: The Gap Between Industry Guidelines and Literature, and the Differences Amongst Industry Sectors. In Advances in Safety Management and Human Factors: Proceedings of the AHFE 2016 International Conference on Safety Management and Human Factors; Springer International Publishing: Orlando, FL, USA, 2016.

61. Parke, B.; Kanki, B.G. Best Practices in Shift Turnovers: Implications for Reducing Aviation Maintenance Turnover Errors as Revealed in ASRS Reports. Int. J. Aviat. Psychol. 2008, 18, 72-85. [CrossRef]

62. Tannenbaum, S.I.; Cerasoli, C.P. Do Team and Individual Debriefs Enhance Performance? A Meta-Analysis. Hum. Factors 2013, 55, 231-245. [CrossRef] [PubMed] 
63. Patankar, M.S.; Taylor, J.C. MRM Training, Evaluation, and Safety Management. Int. J. Aviat. Psychol. 2008, 18, 61-71. [CrossRef]

64. Salas, E.; Burke, C.S.; Bowers, C.A.; Wilson, K.A. Team Training in the Skies: Does Crew Resource Management (CRM) Training Work? Hum. Factors 2001, 43, 641-674. [CrossRef]

65. Taylor, J.C.; Patankar, M.S. Four Generations of MRM: Evolution of Human Error Management Programs in the United States. J. Air Transp. World Wide 2001, 6, 3-32.

66. Lappas, I.; Kourousis, K.I. Anticipating the Need for New Skills for the Future Aerospace and Aviation Professionals. J. Aerosp. Technol. Manag. 2016, 8, 232-241. [CrossRef]

67. Salas, E.; Tannenbaum, S.I.; Kraiger, K.; Smith-Jentsch, A.K. The Science of Training and Development in Organizations: What Matters in Practice. Psychol. Sci. Public Interest Suppl. 2012, 13, 74-101. [CrossRef]

68. Karanikas, N. Using Reliability Indicators to Explore Human Factors Issues in Maintenance Databases. Int. J. Qual. Reliab. Manag. 2013, 30, 116-128. [CrossRef]

69. Kirkpatrick, D. Evaluating Training Programs: The Four Levels; Berrett-Koehler: San Francisco, CA, USA, 1998.

70. Ribeiro, B.; Filipe, P. Dissemination, Exploitation and Communication; EU's Horizon 2020 Research and Innovation Programme: Brussels, Belgium, 2016.

71. Karanikas, N. Human Error Views: A Framework for Benchmarking Organizations and Measuring the Distance between Academia and Industry. In Proceedings of the 49th ESReDA Seminar, Brussels, Belgium, 29-30 October 2015.

72. Malagas, K.; Fragoudaki, A.; Kourousis, K.I.; Nikitakos, N. The Prospects of the Higher Education Aviation Programs in Greece: A Missed Opportunity or a Challenge to Meet? J. Aerosp. Technol. Manag. 2017, 9, 510-518. [CrossRef]

73. Robinson, S.L. Trust and Breach of the Psychological Contract. Adm. Sci. Q. 1996, 41, 574-599. [CrossRef]

74. Butler, J.K.J. Towards Understanding and Measuring Conditions of Trust: Evolution of a Conditions of Trust Inventory. J. Manag. 1991, 17, 643-663. [CrossRef]

75. Mayer, R.C.; Davis, J.H.; Schoorman, F.D. An Integrative Model of Organizational Trust. Acad. Manag. Rev. 1995, 20, 709-734. [CrossRef]

76. Cox, S.; Jones, B.; Collinson, D. Trust Relations in High-Reliability Organizations. Risk Anal. 2006, 26, 1123-1138. [CrossRef]

77. O'Reilly, C.A. Supervisors and Peers as Information Sources, Group Supportiveness, and Individual Decision-Making Performance. J. Appl. Psychol. 1977, 62, 632-635. [CrossRef]

78. O'Reilly, C.A.; Roberts, K.H. Task Group Structure, Communication, and Effectiveness in Three Organizations. J. Appl. Psychol. 1977, 62, 674-681. [CrossRef]

79. Axelrod, R. The Evolution of Cooperation; Basic Books: New York, NY, USA, 1984.

80. Deutsch, M. Cooperation and Trust: Some Theoretical Notes. In Nebraska Symposium on Motivation; University of Nebraska Press: Lincoln, NE, USA, 1962.

81. Earley, P.C. Trust, Perceived Importance of Praise and Criticism, and Work Performance: An Examination of Feedback in the United States and England. J. Manag. 1986, 12, 457-473. [CrossRef]

82. Ben-Ner, A.; Putterman, L. Trust, Communication and Contracts: An Experiment. J. Econ. Behav. Organ. 2009, 70, 106-121. [CrossRef]

83. McAllister, D.J. Affect-And Cognition-Based Trust as Foundations for Interpersonal Cooperation in Organizations. Acad. Manag. J. 1995, 38, 24-59.

84. Zand, D.E. Trust and Managerial Problem Solving. Adm. Sci. Q. 1972, 17, 229-239. [CrossRef]

85. Harvey, C.; Stanton, N.A. Safety in System-Of-Systems: Ten Key Challenges. Saf. Sci. 2014, 70, 358-366. [CrossRef]

86. Taylor, J.C.; Thomas, R.L., III. Toward Measuring Safety Culture in Aviation Maintenance: The Structure of Trust and Professionalism. Int. J. Aviat. Psychol. 2003, 13, 321-343. [CrossRef]

87. Reason, J.T. Organizational Accidents Revisited; CRC Press: Boca Raton, FL, USA; London, UK, 2016.

88. Dekker, S. Drift into Failure: From Hunting Broken Components to Understanding Complex Systems; Ashgate: Farnham, UK; Burlington, VT, USA, 2011.

89. Rasmussen, J. Risk Management in a Dynamic Society: A Modelling Problem. Saf. Sci. 1997, 27, $183-213$. [CrossRef]

90. Leveson, N. A New Accident Model for Engineering Safer Systems. Saf. Sci. 2004, 42, 237-270. [CrossRef] 
91. Jian, J.-Y.; Bisantz, A.M.; Drury, C.G. Towards an Empirically Determined Scale of Trust in Computerized Systems: Distinguishing Concepts and Types of Trust. Proc. Hum. Factors Ergon. Soc. 1998, 1, 501-505. [CrossRef]

92. Ockerman, J.; Pritchett, A. A Review and Reappraisal of Task Guidance: Aiding Workers in Procedure Following. Int. J. Cogn. Ergon. 2000, 4, 191-212. [CrossRef]

93. Patankar, M.S.; Gomez, M. Maintenance ASAP Programs: Barriers and Opportunities; Federal Aviation Agency (FAA): Washington, DC, USA, 2004.

94. McKnight, D.H.; Thatcher, J.B. Trust in Technology: Development of a Set of Constructs and Measures. In Handbook of Trust Research; Zaheer, A., Bachmann, R., Eds.; American Psychological Association: Washington, DC, USA, 2004.

95. McKnight, D.H.; Carter, M.; Thatcher, J.B.; Clay, P. Trust in a Specific Technology: An Investigation of Its Components and Measures. ACM Trans. Manag. Inf. Syst. 2011, 2, 1-25. [CrossRef]

96. McKnight, D.H.; Chervany, N.L. The Meanings of Trust. In MIS Research Center Working Paper Series; University of Minnesota: Minneapolis, MN, USA, 1996.

97. Powell, W.W.; DiMaggio, P.J. The New Institutionalism in Organizational Analysis; University of Chicago Press: Chicago, IL, USA, 1991.

98. Giddens, A. The Consequences of Modernity; John Wiley \& Sons: New Jersey, NJ, USA, 1990.

99. Salam, M.A. The Mediating Role of Supply Chain Collaboration on the Relationship between Technology, Trust and Operational Performance. Benchmarking Int. J. 2017, 24, 298-317. [CrossRef]

100. Arrow, K. The Limits of Organization; Norton: New York, NY, USA, 1974.

101. Zaheer, A.; Bachmann, R. Handbook of Trust Research. Elgar Original Reference; Edward Elgar Publishing: Cheltenham, UK, 2006.

102. Kramer, R.M.; Tyler, T.R. Whither Trust? In Trust in Organizations; Kramer, R.M., Tyler, T.R., Eds.; Sage: Thousand Oaks, CA, USA, 1996.

103. Catino, M. A Review of Literature: Individual Blame vs. Organizational Function Logics in Accident Analysis. J. Conting. Crisis Manag. 2008, 16, 53-62. [CrossRef]

104. Dekker, S.W.A. Just Culture:Who Gets to Draw the Line? Cogn. Technol. Work 2009, 11, 177-185. [CrossRef]

105. Goglia, J.; Patankar, M.S.; Taylor, J.C. Lack of Error Mitigation Tools: The Weakest Link in Maintaining Airworthiness? In Proceedings of the 55th Annual International Air Safety Seminar, Dublin, Ireland, 4-7 November 2002.

106. McKnight, D.H.; Cummings, L.L.; Chervany, N.L. Initial Trust Formation in New Organizational Relationships. Acad. Manag. 1998, 23, 473.

107. Rotter, J.B. A New Scale for the Measurement of Interpersonal Trust. J. Pers. 1967, 35, 651-665. [CrossRef] [PubMed]

108. Hovden, J.; Størseth, F.; Tinmannsvik, R.K. Multilevel Learning from Accidents-Case Studies in Transport. Saf. Sci. 2011, 49, 98-105. [CrossRef]

109. Naevestad, T.O. Safety Cultural Preconditions for Organizational Learning in High-Risk Organizations. J. Conting. Crisis Manag. 2008, 16, 154-163. [CrossRef]

110. Patankar, M.; Driscoll, D. Factors Affecting the Success or Failure of Aviation Safety Action Programs in Aviation Maintenance Organizations; Federal Aviation Administration: Washington, DC, USA, 2005.

111. Donath, J.S. Identity and Deception in the Virtual Community. In Communities in Cyberspace; Smith, M.A., Kollock, P., Eds.; Routledge: London, UK, 1999.

112. Bachmann, R. Trust, Power and Control in Trans-Organizational Relations. Organ. Stud. 2001, 22, 337-365. [CrossRef]

113. Langer, M.; Braithwaite, G.R. The Development and Deployment of a Maintenance Operations Safety Survey. Hum. Factors 2016, 58, 986-1006. [CrossRef]

114. Bureau of Air Safety Investigation Australia. Human Factors in Airline Maintenance: A Study of Incident Reports; Department of Transport and Regional Development Bureau of Air Safety Investigation Australia: Canberra, Australia, 1997.

115. McRoy, S. Preface: Detecting, Repairing and Preventing Human-Machine Miscommunication. Int. J. Hum. Comput. Stud. 1998, 48, 547-552. [CrossRef] 
116. Robertson, M. Maintenance Resource Management. In Human Factors Guide for Aviation Maintenance; Authority, F.A., Ed.; Federal Aviation Administration: Washington, DC, USA, 2005.

117. Hobbs, A.; Williamson, A. Associations Between Errors and Contributing Factors in Aircraft Maintenance. Hum. Factors 2003, 45, 186-201. [CrossRef] 